\title{
CIUDAD ENSIMISMADA, ISLARIOS DEFENSIVOS FRENTE A LA OTREDAD
}

\author{
Irune Sacristan Arana. \\ Tesis de Máster en Gestión Urbana y Valoraciones \\ Universidad Politécnica de Cataluña
}

\author{
Josep Roca Cladera \\ Centro de Política del Suelo y Valoraciones \\ Universidad Politécnica de Cataluña
}

Palabras clave: Ciudad, diversidad, individuo, identidad, alteridad, Otredad, imaginario social, seguridad, islario defensivo, miedo, ensimismamiento.

Resumen: Tantas son las ópticas desde las que se puede abordar el análisis de la ciudad como dispuestos a ello individuos hay. No hay mirada fortuita ni interrogación casual, sino que la dirección y el carácter de la interpelación que cada cual hace ante todo fenómeno, hecho o dinámica depende de su condición de sujeto, como sujeto histórico. Nuestra mirada sobrevuela la ciudad para penetrar en los espacios de la intimidad donde el individuo se muestra como tal, con la esperanza de presenciar el desvelamiento de la relación históricamente unívoca entre el hombre y su tiempo y la (no)ciudad que construye. O en su caso, la ciudad que (de) construye, a la luz de las nuevas formas de urbanización (en)cerradas y dispersas en el territorio características de los asentamientos urbanos contemporáneos. La tesis sostenida es que las citadas dinámicas de desarrollo urbano que conforman la que se ha venido a llamar "Ciudad Ensimismada" tienen su origen en el ensimismamiento propio del individuo contemporáneo; concebido éste como una forma de respuesta colectivamente individual en su esfuerzo por adaptarse al Real imaginario o imaginario social que actúa como generador de diversas patologías entre las que cabe destacar la exacerbación del miedo a la Otredad.

\section{Introducción: Miríada y miradas}

La complejidad de la ciudad deviene de la infinidad de factores, fenómenos y dinámicas que en su constitución y transformación toman parte. Tal es la complejidad del sistema urbano que todo intento de definición del término ciudad requiere de un profundo análisis del fenómeno urbano desde una óptica concreta y debidamente explicitada. Porque los ángulos desde los que cabe ser estudiada son infinitos. Buena muestra de ello es la prolífica bibliografía existente en torno al análisis de la ciudad desde las más diversas ópticas: desde la historia, la antropología, la sociología, la geografía, la economía, la política, el arte y la arquitectura, y un largo etcétera. Porque la cantidad de lugares desde donde cabe ser observada la ciudad trasciende a las ramas del saber en número en tanto que cada individuo es susceptible de analizar la ciudad desde su propia mirada e incluso relatarla a través de la narración poética o novelesca. Con esta reflexión no se pretende justificar cualquier razonamiento mediante la negación de la posibilidad de toda objetividad, sino que se acepta como punto de partida la subjetividad. Se asume el hecho, éste sí objetivo, de que todo observador contempla su objeto de estudio desde un determinado punto de vista ${ }^{(1)}$. En consecuencia, las hipótesis de partida, el razonamiento y las conclusiones versarán sobre las mismas bases que fundamentan el lugar desde donde se mira. Y desde aquí tratamos de mirar la ciudad trascendiendo las propias condiciones materiales, la pura 'objetividad' del mundo para desde la contemplación de la "condición humana" ${ }^{(2)}$ contemporánea aventurarnos a validar la tesis formulada. 
Tras el advenimiento de la "Tercera Revolución" (Cohen, 1998) son muchas las ocasiones en que se ha abordado el estudio de las dinámicas urbanas desde el análisis de las tecnologías de la información y la comunicación (TIC), a través de la observación de las transformaciones que la llamada sociedad de la información ha protagonizado en las últimas décadas. Javier Echeverria ponía de manifiesto, en Telépolis (1994), los cambios provocados en la organización social por la posibilidad que representan para el individuo "telepolitano" de interactuar con tantas otras realidades como él desee. La consecuente desterritorialización del individuo por un lado y la capacidad de los mass media de generar realidades que se ajustan a los intereses de los propios productores del tiempo de ocio y producción mediático minimiza el grado de interacción del hombre "telepolitano" con el entorno local y los grupos sociales de la comunidad. Bauman (2006) por su parte, al igual que lo hiciera Castells (1995), nos presenta una ciudad informacional fragmentada por las clases superiores y las inferiores como consecuencia de la polarización social de ambos grupos. Nos presenta por un lado las clases superiores conectadas al mundo a través de las TIC y las inferiores por el otro, congregadas, localizadas en un lugar cuya agrupación tiene su origen en causas étnicas o nacionales. Las personas del nivel superior no pertenecen por tanto al lugar en el que disponen de su residencia, sino que "habitan" en el medio virtual. Sus preocupaciones están allí depositadas y la ciudad por tanto les es ya ajena y no participan de sus dinámicas

Pero las consecuencias de las TIC no son casuales, sino que responden a condiciones concretas. Porque los efectos del desarrollo de las tecnologías de la información son variables en función con su interacción con procesos políticos, culturales y sociales. Es decir, la organización de la sociedad no viene determinada por la tecnología sino que es la propia sociedad y el sistema económico vigente los que deciden el modo de adaptación a los nuevos desarrollos tecnológicos. Cabe por tanto plantear la honesta duda acerca de la veracidad del análisis de las dinámicas sociales en la ciudad a través del estudio de los fenómenos de polarización y segregación como consecuencia de una sociedad desigualmente informacional. El propio Bauman (2006) argumenta más adelante en Confianza y temor en la ciudad, que a pesar de que el razonamiento esbozado en referencia a las consecuencias de las TIC sobre la organización social contiene muchas verdades, no es la pura verdad. La parte de verdad que queda ausente en los razonamientos y que se presume fundamental en la caracterización de las formas de vida urbana de la contemporaneidad es "la estrecha influencia recíproca que hay entre la presión mundializadora y el modo en que se negocia, se forma y se reforma la personalidad propia de cada lugar". Una ciudad donde los individuos de las clases superiores se defienden hoy frente al riesgo que presentan los "desclasados" ${ }^{(3)}$ mediante su agrupación en islarios defensivos. Porque el hombre "telepolitano" radical, aquél cuyo ámbito de interacción quedaría circunscrito al medio virtual, ajeno al lugar en que habita y al margen por tanto de todo "antisocial" (4), brilla por su ausencia en un mundo en que aun hoy es necesario relacionarse con el medio físico, si no a diario, sí habitualmente. En este mundo que a pesar de los efectos globalizadores, o precisamente por ellos, el poder del ámbito de lo local adquiere cada día mayor preponderancia, el origen de las formas actuales de desarrollo urbano parece haya de ser buscado más allá de las propias condiciones tecnológicas; a través de la lectura de las consecuencias humanas de la globalización. A través de las consecuencias antropológicas de la condición humana contemporánea sobre el individuo.

Introducirse al tema del análisis de la ciudad desde una óptica antropológica y psicosocial es abrir una puerta a la complejidad del Ser en toda su extensión. Desde lo más profundo de la intimidad del individuo hasta el más público de sus rostros, que emerge de su relación para con el Otro a través de la esfera de lo colectivo.

Es abrir una puerta que da paso a una miríada de conceptos relacionales inherentes al individuo en tanto que ser social. Identidad, alteridad, la Otredad, lo real, lo simbólico, lo absoluto, frontera, alteridad e integridad, entre tantos otros, son conceptos clave que a lo largo del presente artículo se irán abordando con una doble finalidad. Primeramente, es necesario clarificar cada uno de los términos empleados permitiendo al lector situarse en el lugar desde donde se ha mirado la ciudad, para posteriormente establecer la relación intrínseca que la 
hipótesis de partida plantea entre la posición que en medio de la vorágine globalizante adopta el sujeto respecto a dichos conceptos, y la ciudad que construye.

Sin duda alguna un trabajo como éste no puede abordar, ni lo pretende, el tema en toda su realidad y complejidad. La atención queda centrada en aquellos aspectos que clarifican la mirada y son susceptibles de arrojar una luz sobre la óptica desde la que ha sido observada la ciudad, asumiendo el riesgo de sesgo que de dicha selección pueda derivar. Y es concretamente desde el análisis de las afecciones propias del hombre contemporáneo ${ }^{(5)}$ que se inicia el presente estudio de la ciudad, de nombre ensimismada.

\section{Identidad y entidad}

Vinculada la identidad ${ }^{(6)}$ a la colectividad, quizás sería más propio hablar de 'identidades'. 'Identidades' que no devienen tan solo del sumatorio del sin fin de individuos diversos, sino de la diversidad de identidades parciales, de "pertenencias" (Maalouf, 1999) constitutivas de cada ser. Porque cada ser individual forma parte de diferentes colectividades con signos de caracterización específicos compartidos por quienes se integran en el grupo. Por tanto, cada uno de nosotros puede identificarse con varios colectivos, compartiendo con los miembros de cada uno de esos grupos unos rasgos específicos de su condición de individuo. En este sentido, cabría hablar de múltiples identidades variables en relación con las condiciones de contingencia espacio temporal. La identidad, así entendida, no puede ser concebida por tanto como una cualidad estática, sino en constante devenir.

La identidad se define además como la "conciencia que una persona tiene de ser ella misma y distinta a las demás" ${ }^{(7)}$, entre otras acepciones. Es precisamente el hecho de ser consciente de mi condición de distinto frente a los demás lo que me confiere identidad. Requiero por tanto del Otro diferente, para reconocerme a mí mismo en mis propios atributos esenciales y adquirir la cualidad de entidad, separada de los demás. Entidad íntegra, en tanto "que no carece de ninguna de sus partes" (8), siempre y cuando se le confiera a la conciencia la posibilidad de reconocerse a sí misma a través de la dialéctica con la diferencia. Es decir, para saberme íntegro, para tener conciencia de mí como entidad íntegra, requiero del Otro dado que es el alejamiento, la separación mediada en la diferencia lo que me da conciencia de ser yo mismo y no otro. La importancia del Otro para el reconocimiento de uno mismo queda reflejada en el pensamiento de Levinas (2000) a través de la ética de la responsabilidad para con el Otro. Porque sin esos Otros, uno queda subsumido a la mismidad, al ensimismamiento, al encerramiento.

\section{Integridad e identidad: mismidad}

El término integridad (del latín integritas), de acuerdo con la Real Academia Española, no es otra cosa que la "cualidad de íntegro". Tal y como apuntamos recientemente, "que no carece de ninguna de sus partes". La condición de íntegro es por tanto condición inherente a dicha entidad, que requiere de lo otro para reconocerse como tal. Por otra parte, integrismo (íntegro) queda definido como la "actitud de ciertos sectores religiosos, ideológicos o políticos, partidarios de la intangibilidad de la doctrina tradicional". Todo afán por el mantenimiento de la identidad de una colectividad requiere por tanto de la defensa a ultranza de sus características identitarias frente a otros, en la creencia de que dichas características, no deben o no pueden tocarse, en su condición de intangibles. La identidad por tanto adquiere la condición de invariable, en contra de su propia naturaleza, sujeta el devenir.

De todo lo dicho podríamos inferir que Occidente parece haber confundido los términos. En la (falsa) necesidad de reconocimiento de su condición de entidad única e íntegra, que por ser inherente al ser en tanto que diferente de todas las otras y completa, ya lo es, ha considerado necesidad de primer orden un cierto grado de integrismo (íntegro) para evitar un eventual desmembramiento o desintegración.

Y en su afán por mantener su (mal entendida) integridad en tanto que identidad siempre idéntica a sí, la civilización Occidental parece estar dispuesta a invisibilizar a todo Otro, a todo diferente radical con el fin de salvaguardar sus rasgos identitarios. Para la consecución de dicha eliminación del Otro de la cotidianeidad, se presentan dos vías yuxtapuestas y 
complementarias; por un lado la integración por canibalización ${ }^{(9)}$ mediante la transformación del Otro en mismidad, y por el otro la estigmatización, a través de la asunción de peligro que suponen esas entidades diferentes.

\section{Integrismo y totalitarismo}

De acuerdo con Levinas (2000) la adaptación del otro a lo mismo requiere de cierta violencia para reducir lo múltiple a la totalidad. Es más, el acto de reducir al otro a mí mismo es más que mera violencia, es dominación. En este sentido, la filosofía occidental en su afán por reducir al otro al igual ha aniquilado la diversidad subsumiéndola a la homogeneidad (Baudrillard, 2006). A la unicidad en tanto que son sus propios rasgos identitarios los únicos que tienen cabida, negando la existencia de espacio alguno donde la alabada multiculturalidad pueda manifestarse.

El otro, en su proceso de transformación a lo uno, se desprende de sus características identitarias ${ }^{(10)}$ para asumir nuevas cualidades, idénticas al colectivo al que se adhiere. No hay por tanto espacio para identificarse con nada que no sea uno mismo, la mismidad. De ahí que la característica básica de la civilización Occidental, es decir su rasgo identitario fundamental, sea el ensimismamiento (Méndez y Jauregui, 2005).

La negación de la diversidad es propia de regímenes totalitarios, autoritarios. Frente al riesgo que supone para la subsistencia de un proyecto social unitario la aceptación de la existencia de otras "condiciones humanas" (Arendt, 2005) en tanto que ejemplificadoras de otras posibles realidades, se opta por su invisibilización. Tal y como apuntábamos recientemente, mediante su canibalización o su estigmatización.

Siendo la civilización occidental la que a menudo presume de su larga vida democrática, quizás no resulte políticamente correcto asociarlas con forma alguna de totalitarismo. $Y$ dado que entrar en disquisiciones en torno a un tema que en sí mismo podría ser objeto de un extenso análisis nos alejaría del propósito (fin) último del presente trabajo, tan solo apuntar la diferencia extrema entre el término sistema o régimen democrático y cultura democrática. Porque la cultura democrática sólo puede consolidarse a través de la superación de la dialéctica entre lo uno y lo demás. Y es precisamente este 'demás' lo que las naciones occidentalizadas se esfuerzan por eliminar de la ecuación en su afán por alcanzar lo que Fukuyama (1992) bautizó como "estado homogéneo universal".

La óptica desde la que cabe afirmar que el totalitarismo no le es ajeno a régimen alguno queda plasmada a través de la palabra de Eduardo Galeano en muchos de sus textos, entre los que cabe destacar para el fin que nos ocupa "La cultura del terror/7" (Galeano, 2006; 145): "El colonialismo visible te mutila sin disimulo: te prohíbe decir, te prohíbe hacer, te prohíbe ser. El colonialismo invisible, en cambio, te convence de que la servidumbre es tu destino y la impotencia tu naturaleza: te convence de que no se puede decir, no se puede hacer, no se puede ser."

Y esa misma cultura del terror, que forma parte del imaginario social en torno a la inseguridad, es la que afirmamos está en la base de la actitud patológica de defensa del individuo frente al otro. En el origen mismo del miedo a la Otredad, a lo diferente radical.

Tal y como ya avanzáramos en párrafos anteriores el poder totalizante de la civilización Occidental, en su afán por mantener eternamente idéntica su identidad, requiere de la eliminación del Otro de la cotidianeidad. Por un lado se promueve la integración del Otro mediante su canibalización, que queda despojado de todo elemento que formara parte de su realidad simbólica. Por otro lado, todo aquel que no esté dispuesto a asumir el proyecto social globalizante y mimetizarse, queda expuesto a la exclusión mediante la estigmatización. El totalitarismo contemporáneo trasciende la consideración clásica de fenómeno histórico y pasa a ser una categoría de explicación filosófica de cuyo análisis no podemos prescindir si se pretende atender al desvelamiento de las causas profundas del estado actual de las dinámicas sociales en el medio urbano y los efectos de dichas dinámicas sobre la ciudad.

\section{Real imaginario e ideología}


Durante las últimas décadas la percepción de vulnerabilidad frente al riesgo y la obsesión por la seguridad han experimentado incrementos desmesurados en relación con la real amenaza de peligro. Y resulta paradójico comprobar cómo precisamente en Europa, uno de los lugares donde la sociedad goza de un mayor grado de seguridad a nivel mundial, la percepción del riesgo que tienen los individuos está en constante aumento. Es precisamente esta sensación de inseguridad la que justifica el miedo. Porque lo Real imaginario, el "simulacro" en palabras de Baudrillard, es vivido por el individuo tan intensamente como lo es aquello que pertenece al orden de lo "Real real" (Zizek, 2006). Así, cualquier intento por confirmar la existencia de peligros reales pierde todo interés porque lo verdaderamente relevante es el hecho de que nos sintamos inseguros, asustados y amenazados.

Este tipo de sufrimiento es de origen social en tanto que deviene de la inseguridad frente a los otros. De acuerdo con la hipótesis sostenida por Bauman (2006), "el tipo de inseguridad actual se distingue claramente por el temor al crimen y a los malhechores. Predomina la desconfianza en los demás y en sus intenciones". El individuo se enfrenta a la inseguridad que provoca el encuentro con entidades diferentes de sí mismo de los cuales todo desconoce excepto aquella parte que el propio estado globalizado haya convenido mostrar a través de los mass media y el sistema "(des)educativo" (Chomsky, 2001), entre otros. Es a través de la deformación de la realidad mediante la transmisión de información parcial generada por el sistema en beneficio propio que los individuos como colectividad producen el imaginario social. Parece entonces probable que estemos enfrentándonos a un peligro simulado que enmascara el riesgo real que para la civilización Occidental supone la aceptación de la diversidad en la consecución de su proyecto social. Un proyecto social unitario que trascendiendo los límites de la propia comunidad local (regional, comarcal, estatal, etc.) pretende instaurarse en muy diversos lugares. Un proyecto que adquiriría así la condición de único por globalizado. Quedaría así desbancada toda posibilidad de concebir toda otra realidad, y sobrevendría la instauración del mencionado "estado homogéneo universal" cuya base ideológica no sería otra que la de la propia civilización Occidental.

Tras las políticas parciales de integración social y bajo el estandarte del manido término multiculturalismo Occidente tan solo acoge en su llegada a todas aquellas entidades en origen diferentes, que estén dispuestas a mimetizarse consigo, a transformarse en idénticas a sí misma. A través de la canibalización quedan invisibilizados, camuflados en la selva de la repetición, de la no diferencia. Será la fracción resto, la que se instale en la negativa a perder sus rasgos simbólicos, su identidad, la que sea objeto de estigmatización a través del aparato productor de imaginario colectivo. Y excluidos irrevocablemente, no serán ya nunca dignos de confianza. Recaerá eternamente sobre ellos la duda radical en torno a sus intenciones y serán temidos por los integrados, incluso por aquellos con quienes en origen compartían rasgos comunes, convencidos ya de la necesidad de salvaguardar el sistema en la creencia de que es éste el único y mejor estado (régimen) posible.

Este fenómeno de producción del imaginario social de inseguridad frente al otro se viene desarrollando a nivel global en todos y cada uno de los estados occidentalizados, y son varios los factores que facilitan su expansión. Por un lado la debilitación de los vínculos sociales de individuos que apenas ya sí se relacionan con el ámbito local, y por el otro un grado de anomia debida a la dificultad de adaptación a la cada vez mayor velocidad con que se producen los cambios (Campos y Green, 2005), y que provocan el aumento del grado de incertidumbre del hombre para con el entorno. Y la incertidumbre para aquellos que no han sido educados en ella es fuente de infinita angustia. En tales circunstancias, el individuo temeroso por el afuera incierto asimila con naturalidad todo mensaje de alerta en relación con la inseguridad. Serán los propios individuos temerosos quienes retroalimenten el imaginario colectivo.

Así, el individuo contemporáneo parece ser cada vez más un ente cuya función primera sea el intercambio acelerado de materia, energía y/o información útil para el propio sistema. Ese individuo autónomo que se traslada rápida y eficazmente es sometido a un estado de alienación creciente que lo mantiene al margen de la esfera de lo colectivo, es decir de la política y la comunidad. Este nuevo individuo que actúa al margen de la condición humana de la pluralidad se ve así desposeído de la actividad que es propia de la "vita activa" (Arendt, 
2005; 35), esto es, de la acción. El aislamiento al que se ve sometido erradica toda posibilidad de participación en la vida política, pues ésta sólo se manifiesta en la vida en comunidad, en sociedad. 


\section{Encierro y ensimismamiento: islarios defensivos en la ciudad}

Este individuo adaptado a las condiciones humanas contemporáneas representa la fracción visible y aceptada de la comunidad global. El colectivo al que pertenece es un colectivo "clasificado", reconocido y avalado por la comunidad tanto local como global por tratarse de entidades que encajan en el orden establecido de acuerdo con lo que hemos venido a denominar proyecto social hegemónico del sistema totalitario Occidental. Se trata de individuos que a diferencia de los "desclasados" [underclass] (Bauman, 2006; 16) son parte activa en el establecimiento y mantenimiento del nuevo orden. Porque tal y como en toda reforma del estado de las cosas existen elementos no reutilizables, así también el establecimiento del nuevo orden requiere prescindir de aquellas entidades que ya no le son útiles. Es aquí donde Bauman sitúa el origen de la existencia de los "desclasados", que bien podrían representar la Otredad. Esos 'otros' que ya no solo proceden de lugares remotos, ajenos al proyecto social totalizante, sino que se encuentran y se generan en el interior de las propias ciudades donde el nuevo orden ya ha sido instaurado.

Se produce así una fractura social a través de la clasificación propia del sistema de codificación binario occidental: los 'sistematizados' (11) y los otros, es decir, el resto. Y lo que es más importante; dicha clasificación no es susceptible de sufrir modificación alguna dada la condición de irrevocabilidad que entraña el hecho de ser excluido por prescindible, quedando subsumido indefinidamente en la marginación, la estigmatización e incluso la invisibilización.

Los "desclasados", a los ojos de los adaptados ya no son más que un conjunto de otredades, una masa de entidades desconocidas y por tanto temidas. Esos otros son por tanto fuente de los temores que movilizan a los adaptados en orden a establecer los sistemas defensivos necesarios para mantenerlos alejados. Y la manera de protegerse no es otra que la que históricamente ha venido empleándose: mediante la consolidación de fronteras ${ }^{(12)}$. Pero las fronteras contemporáneas, a diferencia de las tradicionales, son trazadas en el interior de las propias ciudades. No definen pues el área intra y extra muros de la ciudad histórica sino que delimitan áreas donde 'no se debe ir' si se busca mantenerse alejado de los riesgos, y áreas de seguridad. Son estas áreas de aparente seguridad, dotadas de cercas, cámaras de videovigilancia, sistemas de alarma y demás sistemas defensivos, donde se instalan y se congregan los 'sistematizados'. Donde se encierran voluntariamente en comunidades de presuntos idénticos que frente al temor que suscita el desconocimiento absoluto respecto a las intenciones de los desconocidos, deciden aislarse del entorno. Movido por el ansia de encontrar un pequeño lugar de sosiego, seguridad y certeza, donde no existe posibilidad de interacción con desconocidos, el individuo 'de clase' (13) decide su propio encerramiento. Un encerramiento de individuos que bien podrían ser el mismo repetido; un ensimismamiento en toda regla.

Estas urbanizaciones residenciales cerradas que responden a la doble necesidad de encerramiento de entidades 'iguales' (equivalentes) por un lado, y de defensa frente al diferente radical por otro, son hoy la materialización paradigmática de esta nueva forma de mirar, entender y estar en el mundo, y por tanto de las nuevas formas de ocupación del territorio. Las gated communities ${ }^{(14)}$ confieren al individuo la ilusión de seguridad frente al peligro que suponen los otros, siempre y cuando se mantenga dentro de los límites interiores, sometido al encerramiento, pues es en los espacios desprotegidos que quedan fuera del encierro donde se puede producir el indeseado encuentro con el otro diferente, con el desconocido.

La agrupación espacial de colectivos de 'idénticos' en el territorio tiene importantes consecuencias en la configuración de la ciudad: a) se produce una especialización "de clase" caracterizada por la diferencia de poder adquisitivo de los habitantes de cada área residencial. Por un lado, los "sistematizados", que son considerados contribuyentes, es decir que aportan y por tanto merecen ser reportados (recompensados, retribuidos) y por el otro lado los "desclasados", de los que puede prescindirse pues solo generan gastos. Las áreas de los "desclasados" quedan así abocadas a la degeneración, la marginación y el olvido, b) la consolidación de tales áreas residenciales requiere de la construcción de muros, vallas y cercas con el fin de materializar el límite que separa el espacio protegido del exterior. Tal separación provoca la fragmentación de un espacio donde lo colectivo no es más que el 
espacio intersticial residual entre la colección de islarios privatizados autónomos, c) la agrupación de individuos idénticos en 'clase' trasciende el ámbito residencial dando origen a la especialización funcional del territorio mediante la construcción de clusters donde cada actividad específica pueda desarrollarse en condiciones de seguridad. Se desarrollan así complejos monofuncionales 'de clase' (centros comerciales, complejos turísticos, clubes deportivos, etc.), donde quedan 'naturalmente' excluidos los "desclasados" por no disponer de poder adquisitivo suficiente para disfrutar de tales actividades, d) el interés individual de agentes específicos se antepone al beneficio colectivo, dado que sólo los "sistematizados" pueden optar por consolidar áreas que satisfagan sus necesidades mediante la promoción privada. Así la ciudad no se construye por el bien común sino que resulta del sumatorio de intervenciones movidas por el interés individual de colectivos de idénticos, e) el aislamiento que supone el encierro voluntario de los individuos 'de clase' en relación con su entorno próximo provoca la desvinculación de éstos con todo aquello que tiene lugar en el ámbito local. Es decir, se pierde todo interés por cuestiones que afectan a la propia ciudad, pues el individuo tan solo se ocupa de lo que acontece al interior de su islario defensivo. El espacio que circunda tales islarios únicamente se emplea para trasladarse.

En este sentido cabe decir que este individuo contemporáneo (adaptado) no habita ya más la ciudad, a la manera Heideggeriana, sino que la transita. Se desplaza por ella de una fortificación a otra, aumentando incluso su velocidad en el trayecto entre clusters para minimizar el tiempo de exposición al presunto peligro que supone la interacción con todo aquello ajeno a su pequeño universo conocido. Los "no lugares" de Marc Augé (1998) parecen haberse extendido a la totalidad de lo que un día fuera el espacio público de una ciudad donde a penas se produce ya interacción alguna entre individuos. Sitios, más que lugares, cuyas características dominantes son el movimiento, la velocidad, la aceleración constante, y la interacción asincrónica entre agentes dispersos que comparten 'clase', encierro y el poder adquisitivo que les dota de acceso exclusivo a las TIC. Asistimos pues a la construcción de entornos de exclusión instalados en la inmensidad del "no lugar", que no son más que la materialización del propio (des)orden social. A la anulación de la esfera de lo colectivo, a la trivialización/banalización del entorno común, que no es ya espacio público sino mera extensión de tránsito.

La seguridad, avalada por la necesidad de respuesta frente al temor que suscita la sensación de riesgo frente a un posible encuentro con los otros, es hoy un producto mercadeable. Y la producción arquitectónica y urbanística contemporánea no escapa a tales demandas. Urbanistas y arquitectos, se afanan en la búsqueda urgente de soluciones que satisfagan tales demandas. Es así como la arquitectura del miedo y las urbanizaciones defensivas son los productos por excelencia del mercado inmobiliario ${ }^{(15)}$. Pero lejos de paliar la sensación de inseguridad, ésta continúa experimentado un extraordinario incremento. Porque cuanto mayor es la separación entre entidades diferentes, mayor es el desconocimiento del otro y por tanto la incertidumbre y el recelo que suscita ${ }^{(16)}$. $Y$ dicha incertidumbre no hace sino incrementar la sensación de riesgo. La segregación que se produce en la ciudad entre los sistematizados y los otros a través de la consolidación de áreas específicas y delimitadas para cada uno de los colectivos no hace por tanto sino repercutir negativamente sobre el problema que en origen se planteaba solventar. En lugar de promover la interacción de entidades diversas, a través de cuyo contacto podría verse reducida la incertidumbre ante todo desconocido, las urbanizaciones cercadas y la arquitectura defensiva buscan asegurar la imposibilidad de que tal encuentro se materialice.

Es así como en esta ciudad ensimismada, el espacio público pierde su razón de ser por antonomasia. Este espacio, lejos de ser el soporte donde se promueve la interacción de anónimos que se encuentran, se miran humanamente y se reconocen en la diferencia, es una mera extensión a través de la cual es preciso desplazarse velozmente a fin de que dicho encuentro no se produzca. A lo sumo, este espacio puede ser soporte para la interacción de agentes que forman parte del engranaje de la maquinaria que dinamiza el desarrollo económico sobre el que se erige el proyecto social de todo 'estado del bienestar'. Las intervenciones urbanas destinadas a anular toda posibilidad de encuentro con la diversidad 
tienen un importante efecto secundario: se eliminan también todas aquellas características atractivas ${ }^{(17)}$ propias de la ciudad que son las están en el origen de la mixofilia ${ }^{(18)}$ y sin cuya existencia, afirma Bauman, la mixofobia ${ }^{(19)}$ a buen seguro ganará la batalla del miedo, la segregación y el tedio. El propio Bauman define la siguiente cuestión como el dilema primordial al que arquitectos y urbanistas habrán de hacer frente: "¿Es posible erradicar el miedo suprimiendo igualmente el tedio?"

A tenor de los productos inmobiliarios contemporáneos que casi con total exclusividad se plantean desde la asunción de que para reducir el grado de riesgo frente al afuera incierto es necesario defenderse mediante la separación, parece lógico pensar que no existe más camino que éste. Pero desde aquí y ahora, desde la alegría que provoca el "sentipensar" (20) que existe una 'cuarta vía' (21) para la elaboración del proyecto común de la ciudad, se pretende dejar la puerta abierta a la esperanza. Porque es más que probable que tal cuestión siquiera haya sido aun formulada por el grueso de los agentes sociales. Porque tal cuestión sólo puede ser planteada desde la conciencia de saberse uno porque existen otros, desde la mirada siempre dispuesta a la transformación por interacción con lo desconocido. Es deber fundamental de arquitectos y urbanistas replantearse el estado de las cosas, al margen de la mera demanda retroalimentada por el propio negocio inmobiliario del terror. Sólo así podremos avanzar en el camino hacia la restauración de las características positivas y generadoras de sentimientos 'mixofílicos' de nuestras ciudades, para hacer frente al creciente grado de "mixofobia". No se me ocurre tarea más urgente que ésta si aun queremos habitar humanamente el mundo.

Otro "modo de ser" (22)

Ante tal necesidad, y a pesar o precisamente porque tal y como se ha venido manteniendo en el presente artículo el origen de los fenómenos que se vienen desarrollando en las ciudades son de origen global, quizás debiéramos comenzar aquí y ya; en el ámbito local, que es donde la política tiene su razón de ser y donde se materializa la "vita activa". Porque es precisamente en la ciudad, donde tradicionalmente se ha venido produciendo la mayor acumulación de individuos desconocidos entre sí donde podemos (re)aprehender a vivir en comunidad, a través de la interacción, la palabra y la "responsabilidad para con el otro" (Levinas, 2000).

A tal efecto resulta ésta sí, prioridad de primer orden, disponer del soporte donde tal interacción entre sujetos pueda tener lugar. Es por tanto responsabilidad de arquitectos y urbanistas hacer una revisión crítica del panorama actual con el fin de replantearse el ejercicio de esta profesión hoy, que tradicionalmente ha velado por el bien común. Porque de lo que no cabe ninguna duda es que una ciudad sin alma, es decir sin comunidad, no pasa de ser un conglomerado de edificaciones. Es lícito pensar que algún día tal y como ya ocurriera tiempo atrás, osemos proponer acciones contrarias quizás a intereses particulares concretos en favor de la construcción de nuestro lugar común.

\section{Notas}

1. Esta idea queda formulada través de las palabras de Einstein en torno a la realidad, tomadas de la introducción que Ramon Folch desarrolla en el libro El territorio como sistema: "Ios hechos son los hechos, pero la realidad es su percepción". En este sentido, el observador se presenta como un creador parcial, no en sentido de demiurgo sino en tanto que narrador de la realidad.

2. Hannah Arendt $(2005 ; 37)$, hace uso de la expresión "condición humana" para referirse al orden de cosas, a las circunstancias creadas y autoproducidas constantemente por el hombre y que complementan la "objetividad del mundo". Porque, según sus propias palabras "La objetividad del mundo -su carácter de objeto o cosa- y la condición humana se complementan mutuamente; debido a que la existencia humana es pura existencia condicionada, sería imposible sin cosas, y éstas formarían un montón de artículos no relacionados, un no mundo, si no fueran las condiciones de la existencia humana".

3. Mediante el término desclasado [underclass], Bauman $(2006 ; 16)$ hace referencia a "hombres y mujeres que no pertenecen a ningún grupo social legítimo, individuos situados al 
margen de cualquier clase, a los que no corresponde ninguna de las funciones aprobadas, útiles e indispensables que desempeñan los ciudadanos 'normales'; personas que no aportan nada a la sociedad, salvo lo que es prescindible y no interesa."

4. Ibidem. El propio Bauman utiliza el término "antisocial" para referirse a dos grupos de individuos: "los desclasados y los delincuentes no son más que dos subconjuntos de los elementos antisociales".

5. La tesis planteada se sostiene sobre la hipótesis de que existe una relación unívoca entre el modo de ser del hombre y la ciudad que construye. Fernando Chueca Goitia (2002; 8), ponía de manifiesto la existencia de tal relación cuando afirmaba que "Todo lo que al hombre le afecta, afecta a la ciudad (...)".

6. Identidad (Del b. lat. Identitas, -atis): Conjunto de rasgos propios de un individuo o de una colectividad que los caracterizan frente a los demás. (Real Academia Española, Diccionario de la Lengua Española, $22^{\circ}$ Ed., Madrid, Espasa Calpe)

7. Ibídem.

8. Ibídem.

9. El término canibalización pretende poner de manifiesto la violencia con que todo aquel cuyo objetivo sea integrarse en la comunidad occidental es sometido a despojarse de los rasgos identitarios propios. Este modo de integración responde a la forma contemporánea del multiculturalismo, que tal y como Zizek apunta en varios textos, "comprende una cultura que tiende a considerar que todas las culturas, excepto ella misma, son diferencias particulares, y que tolera todo excepto la crítica" (Daly, 2006; 9).

10. Características identitarias tanto de orden real como simbólico. Baudrillard (2006) define este desafío que Occidente plantea como "un desafío de orden simbólico: una aniquilación física y mental, una carnavalización universal que Occidente impone a todas las singularidades que se le resisten al precio de su propia humillación y de su expropiación simbólica".

11. Mediante el término 'sistematizados' se pretende denominar a los adaptados al sistema, los integrados, los útiles; aquellos que Bauman (2006) define como "normales". Se plantea por tanto como antónimo al término "desclasados" empleado por el mismo autor.

12. Resulta sumamente importante el propio acto de trazar tal frontera, el límite entre dentro y fuera, porque éste es el acto que está en el origen de la gestación de las diferencias. Bauman (2006; 61) expresa este hecho afirmando que "emprendemos la búsqueda de diferencias justamente para legitimar fronteras".

13. El término 'de clase' hace referencia a los 'sistematizados' por no pertenecer a los "desclasados". Se pretende así poner de manifiesto que la exclusión entre colectivos actualmente no se produce tanto entre grupos de individuos pertenecientes a diferentes clases sociales sino entre los "desclasados" y los 'de clase'. La diferencia fundamental radica en el hecho de que mientras en la estructura social tradicional de clases el individuo era susceptible de modificar su status, aquellas entidades catalogadas como "desclasados" quedan hoy excluidos permanentemente del sistema. Es decir, su condición de "antisocial" es irrevocable.

14. El término gated communities se emplea en sustitución de barrios cercados, urbanizaciones cerradas, islarios defensivos o clusters. Todos ellos se refieren a aquellas urbanizaciones residenciales caracterizadas por la instalación de sistemas de defensa frente al medio circundante. En función del poder adquisitivo del colectivo que se prevé instalar en dicha urbanización, estarán dotadas de más o menos sistemas: muros, cercas y vallas, cámaras de videovigilancia, guardias de seguridad, sistemas de alarma, etc.

15. El marketing inmobiliario se orienta precisamente a ofrecer productos que satisfagan la supuesta necesidad de protección de los potenciales compradores. La gran mayoría de las promociones inmobiliarias actuales explotan el negocio el miedo: "Piso en urbanización cerrada con seguridad 24 horas (...)"; "Polo Gardens contará con un sistema anti-intrusión en todo su perímetro y circuito cerrado de TV, así como centro de control de seguridad en el acceso a la urbanización (...)"; "Ubicado en la localidad almeriense de Vera, se trata de una urbanización cerrada con control de acceso y diferentes medidas de seguridad, como cámaras de vigilancia en su perímetro o sistema de portero automático para el acceso a la vivienda". (Fuentes: es.green-acres.com; www.spainhouses.net; www.guiadeprensa.com/construccion). 
16. Bauman (2006; 70) hace referencia a Richard Sennett para exponer el círculo vicioso en el que hemos quedado inmersos al optar por la separación y la segregación como vía para hacer frente al estado actual de inseguridad. Porque en palabras del propio Sennett, "(...) cuanto más se separan las personas, en estos barrios cercados de hombres y mujeres que se les asemejan, menos capaces son de tratar con extranjeros; y a su vez, cuanto menos capaces on de tratar con extranjeros, mayor miedo les tienen; por consiguiente, buscan cada vez con mayor avidez la compañía de sus semejantes."

17. Citar todas y cada una de las características atractivas propias de la ciudad requeriría de un análisis pormenorizado de un sinfín de muestras. Pero algunas de estas características inherentes al propio concepto de ciudad nos interesan especialmente por su condición de generadoras de "mixofilia": "(...) su espontaneidad, su flexibilidad y su capacidad de sorprender y ofrecer aventura" (Bauman 2006; 51).

18. La "mixofilia" en palabras de Bauman (2006; 70) "(...) es un fuerte interés, una propensión, un deseo de mezclarse con las diferencias, o sea, con los que son distintos a nosotros, porque es muy humano y natural, y fácil de comprender, que mezclarse con extranjeros abre la vía a aventuras de todo tipo, a la aparición de cosas interesantes, fascinantes."

19. La "mixofobia" se presenta como el término opuesto a la "mixofilia" y es definida por el propio Bauman $(2006 ; 32)$ como "(...) una reacción previsible y generalizada ante la inconcebible, escalofriante y angustiosa variedad de tipos humanos y costumbres que coexisten en las calles de las ciudades contemporáneas y en sus barrios más corrientes (...)."

20. Los textos de Eduardo Galeano, aunque quizás no siempre de manera explícita son la materialización del "sentipensar". Mediante este término queda caracterizada la acción que trasciende la pura reflexión intelectual a través de la articulación del pensamiento y la emoción. Dicho término es elogiado en "Celebración de las bodas de la razón y el corazón" (Galeano, 2006; 107): “¿Para qué escribe uno, si no es para juntar sus pedazos? Desde que entramos en la escuela o la iglesia, la educación nos descuartiza: nos enseña a divorciar el alma del cuerpo y la razón del corazón. Sabios doctores de Ética y Moral han de ser los pescadores de la costa colombiana, que inventaron la palabra sentipensante para definir el lenguaje que dice la verdad."

21. Frente a la actitud de la izquierda de la Tercera Vía que parece no estar dispuesta a "arriesgar lo imposible" (Zizek 2006; 26), se propone otra vía, otro modo de ser mediante la práctica de la acción. Porque de las tres actividades propias de la "vida activa" (labor, trabajo y acción), es a ésta, la acción la que "(...) corresponde a la condición humana de la pluralidad (...), pluralidad (que) es específicamente la condición -no sólo la conditio sine qua non, sino la conditio per quam- de toda vida política" (Arendt, 2005; 35).

22. Se concluye el presente artículo haciendo referencia al ser, no como sustantivo sino en tanto que "modo de existencia del hombre" (Lévinas, 2000), con el fin de hacer énfasis en la idea ya esbozada a lo largo de los párrafos anteriores: la necesidad de asumir, en tanto que hombres y mujeres la responsabilidad de la "vita activa" (Arendt, 2005), en el convencimiento de que es ésta la vía para reconquistar el modo de habitar 'heideggeriano',

\section{Bibliografía}

AAVV (2004). La arquitectura de la no-ciudad. Curso "La arquitectura de la no ciudad", dirigido por Félix de Azúa, Pamplona, del 3 al 7 de marzo de 2003, Pamplona, Universidad Pública de Navarra.

AAVV (2002). Antropología y complejidad, Barcelona, Editorial Gedisa, compilación de Rafael Pérez-Taylor.

ARENDT, Hannah (1958). * La condición humana, Barcelona, Paidós, 2005.

ASCHER, François (2004) Los nuevos principios del urbanismo, Madrid, Alianza Editorial.

AUGÉ, Marc (1998). Los no lugares. Espacios del anonimato. Una antropología de la sobremodernidad, Barcelona, Editorial Gedisa.

BAUDRILLARD, Jean 2006). La agonía del poder, Madrid, Círculo de Bellas Artes. 
BAUMAN, Zygmunt (2006). Confianza y temor en la ciudad. Vivir con extranjeros, Barcelona, Arcadia.

BERRY, Brian J.L. (1975). Consecuencias humanas de la urbanización, Madrid, Pirámide.

BOHIGAS, Oriol (2004). Contra la incontinencia urbana. Reconsideración moral de la arquitectura y la ciudad, Barcelona, Electa.

CAMPOS, Diego y GREENE, Ricardo (2005). "La ciudad y el miedo" en AAVV, VII Coloquio de Geografía Urbana, Girona, Ediciones Universidad de Girona, pp. 87-94.

CAPEL, Horacio (2005). El modelo Barcelona: Un examen crítico, Barcelona, Ediciones del Serbal.

CASTELLS, Manuel (1995). La ciudad informacional, Madrid, Alianza Editorial.

CHOMSKY, Noam (2001). El terror como política exterior de Estados Unidos, Buenos Aires,

Zorzal.

CHOMSKY, Noam (2001). La (des)educación, Barcelona, Crítica.

CHUECA GOITIA, Fernando (1998). Breve historia del urbanismo, Madrid, Alianza Editorial.

COHEN, Daniel (1998). Riqueza el mundo, pobreza de las naciones, Buenos Aires, Fondo de Cultura Económica.

DELEUZE, Gilles y GUATARI, Félix (1977). Rizoma (Introducción), Valencia, Editorial Pre-

ECHEVERRIA, Javier (1999). Telépolis, Barcelona, Editorial Destino.

EDWARS, Brian (2004). Guía Básica de la Sostenibilidad, Barcelona, Editorial Gustavo Gili.

EINSTEIN, Albert (2006). Mi visión del mundo, Barcelona, Tusquets Editores.

FOLCH i GUILLEM, Ramon (2003). "Introducción" en AAVV, 3. El territorio como sistema.

Conceptos y herramientas de ordenación. Curso CUIMPB "El territorio como sistema.

Conceptos y herramientas de ordenación", Noviembre 2003, al cuidado de Ramon Folch,

Barcelona, Diputació de Barcelona.

FUKUYAMA, Francis (1992). El fin de la historia y el último hombre, Buenos Aires, Planeta.

GALEANO, Eduardo (2001). Tejidos. Antología, Barcelona, Ediciones Octaedro.

GALEANO, Eduardo (2005). Patas arriba. La escuela del mundo al revés, Buenos Aires, Siglo $X X I$ de España Editores.

GALEANO, Eduardo (2006). El libro de los abrazos, Madrid, Siglo XXI.

KUNDERA, Milan (1999). La lentitud, Barcelona, Tusquets Editores.

LÉVINAS, Emmanuel (1982). *, Etica e infinito, Madrid, A. Machado Libros, 2000.

LUHMANN, Niklas (1975).* Poder, Barcelona, Anthropos, 1995.

MACHARG, Ian (1977).* Proyectar con la Naturaleza, Barcelona, Editorial Gustavo Gili, 2000.

MENDEZ, Pablo y JAUREGUI, Inmaculada. (2005) "Identidad y Patología; Occidente, una civilización ensimismada", Revista Observaciones Filosóficas, № 1, Edición electrónica.

MITCHEL, William (2001). e-topía. Vida urbana, Jim, pero no la que nosotros conocemos, Barcelona, Editorial Gustavo Gili.

MORRIS, William (1968). Noticias de ninguna parte, Madrid, Editorial Ciencia Nueva.

RODRIGUEZ, Isabel, MENDEZ, Eloy y LOPEZ, Liliana (2006). Espacio Urbano, exclusión y frontera norte de México, Madrid, Ediciones UAM.

ROJAS, Marcos. (1992) La ciudad y sus desafíos. Héroes y víctimas, Madrid, Espasa Calpe.

SABATO, Ernesto (2006). El túnel, Buenos Aires, Grupo Editorial Planeta.

SANTÔKA, Taneda (2006). El monje desnudo, Madrid, Miraguano Ediciones.

SAURA, Carles (2003). Arquitectura y Medio Ambiente, Barcelona, Ediciones UPC.

VIRILIO, Paul (1999). La bomba informática, Madrid, Ediciones Cátedra.

VIRILIO, Paul (1999). El cibermundo, la política de lo peor, Madrid, Ediciones Cátedra.

ZIZÊK, Slavoj y DALY, Glyn (2006). Arriesgar lo imposible, Madrid, Editorial Trotta.

Los libros citados en la presente bibliografía son los consultados, cuya fecha de edición es la indicada entre paréntesis, a excepción de los indicados. En estos casos, dado que existe un importante lapso de tiempo entre el original y la traducción castellana, a fin de presentar las aportaciones de cada autor en orden cronológico la fecha facilitada entre paréntesis se refiere a la edición original. La edición consultada es la que se indica al final de la referencia. 